\title{
Screening for gestational diabetes mellitus: the Sri Lankan experience
}

\author{
CN Wijeyaratne ${ }^{1}$, S Ginige ${ }^{2}$, A Arasalingam ${ }^{3}$, C Egodage $^{3}$ and K Wijewardhena ${ }^{4}$
}

(Index words: Community screening, OGTT cut-off values)

\begin{abstract}
Objective To evaluate tests used for screening and confirmation of gestational diabetes mellitus (GDM) in Sri Lanka.

Methods Field based: Consecutive pregnant women in Homagama DDHS area $(n=853)$, were assessed for risk factors and subjected to random and postprandial urinary Benedict's and Dipstick ${ }^{\circledR}$ tests, fasting and 2 hour post $75 \mathrm{~g}$ glucose capillary blood glucose (FBG and $2 \mathrm{hBG}$ ) which were validated against $75 \mathrm{~g}$ oral glucose tolerance test (OGTT) performed at 24-28 weeks (WHO criteria).
\end{abstract}

Hospital based: Retrospective analysis of consecutive high-risk women $(n=999)$ and prospective study of randomly selected GDM women $(n=66)$ to assess predictive value of the OGTT.

Results Field based: Sensitivity and specificity respectively of random urine Benedict's, $10 \%, 99.2 \%$; postprandial urine Benedict's, 52.2\%, 94.5\%; postprandial urine Dipstick ${ }^{\circledR}, 68.7 \%$, 90\%; capillary FBG threshold $4.1 \mathrm{mmol} / \mathrm{l}, 62.6 \%, 73 \%$; capillary $2 \mathrm{hBG}$ threshold $7.2 \mathrm{mmol} / \mathrm{l}, 98.5 \%, 95.2 \%$; risk factors, $93.1 \%, 22.2 \%$.

Hospital based: OGTT-11.6\% lag curves, $16.3 \%$ abnormal, FPG accuracy at $4.7 \mathrm{mmol} / \mathrm{l}$; predictive value of $2 \mathrm{hPG} \geq 8.9 \mathrm{mmol} / \mathrm{l}$ for insulin treatment-sensitivity $97.2 \%$, specificity $71.4 \%$.

Conclusions Current practice of random urine testing in community screening for gestational diabetes is unreliable, and glucose specific postprandial urine test improves sensitivity. FPG is unsuitable for screening, the 2 hour post $75 \mathrm{~g}$ blood glucose at a threshold of $>7.2 \mathrm{mmol} / \mathrm{l}$ is sensitive and specific. In laboratory confirmation using $75 \mathrm{~g}$ OGTT the fasting plasma glucose has low predictive value, 2 hour test performed alone is liable to false positives and 2 hour glucose $>8.9 \mathrm{mmol} / \mathrm{l}$ following a peak at 1 hour suggests the need for insulin treatment.

\section{Introduction}

Gestational diabetes mellitus (GDM) is defined as carbohydrate intolerance resulting in hyperglycaemia of variable severity, with onset or first recognition during pregnancy, and irrespective of whether or not insulin is required or the condition persists after pregnancy [1-3]. There is a rise in the prevalence of GDM in Sri Lanka. We reported from a community based assessment in 2003 that the age standardized prevalence was $10.3 \%$ [4], which is in keeping with global trends of increasing obesity, type 2 diabetes mellitus and GDM [5]. In our current practice, pregnant women who meet the WHO diagnostic criteria for diabetes mellitus or impaired glucose tolerance (IGT) following a $75 \mathrm{~g}$ oral glucose tolerance test (OGTT) are classified as having GDM. However, much confusion surrounds screening for glucose intolerance during pregnancy in terms of who should be screened, how to screen, and the management of those with positive screening tests. There has been no large scale, well designed, community based study to determine optimal screening for GDM in Sri Lanka. The maternal and child health $(\mathrm{MCH})$ programme in Sri Lanka needs to be recommended a suitable screening test for implementation through its prevailing infrastructure to enable universal screening for GDM, where the screening test positive subjects need to be subjected to the diagnostic OGTT. Furthermore, the predictive value of the diagnostic thresholds of the OGTT in treating GDM and pregnancy outcome viz. birth weight and perinatal mortality needs to be resolved for our community.

We determined the optimal screening method for GDM in a community based study at primary care level (using capillary whole blood) and the optimal use of the OGTT for confirming the diagnosis of GDM in an institutional based setting at tertiary care level (using venous plasma and a three point OGTT).

\section{COMMUNITY BASED SCREENING FOR GDM \\ Method}

A community survey was conducted using multistage cluster sampling to determine the proportion of pregnant women registered by the public health midwives (PHM) in the Homagama DDHS area (rural), which revealed that $99.6 \%$ of pregnant women registered before the 14th week of period of amenorrhoea (POA). All pregnant women registered for antenatal care between 1st April 2003 and 30th July 2003, excluding those with established glucose intolerance, were subjected to selected screening tests that were validated against the $75 \mathrm{~g}$ OGTT (gold standard) performed using capillary blood at POA of 24-28 weeks. Venous whole blood

${ }^{1}$ Professor in Reproductive Medicine, ${ }^{2}$ Senior Registrar in Community Medicine, ${ }^{3}$ Demonstrators in Obstetrics and Gynaecology, Department of Obstetrics and Gynaecology, Faculty of Medicine, University of Colombo, Sri Lanka. ${ }^{4}$ Professor, Department of Community Medicine, Faculty of Medical Sciences, University of Sri Jayawardhenapura. Correspondence: CNW, e-mail: <mandika59@ hotmail.com> (Competing interests: none declared). Funding of communitybased study: World Health Organization. Received 11 October 2005 and accepted 17 October 2006. 
glucose estimation was carried out using Accutrend ${ }^{\circledR}$ alpha glucometer immediately after blood sampling. We validated this method against the standard laboratory venous plasma glucose $(\mathrm{PG})$ measurement prior to the study and found that the two sets of measurements were comparable $(p>0.05)$. A further $5 \%$ sub-sample of capillary blood glucose assessments performed in the field was validated against the corresponding venous blood samples collected simultaneously. The diagnosis of GDM was made based on WHO recommendations for capillary and venous diagnostic criteria (Table 1) [6], where the venous sample values measured using a laboratory autoanalyser were considered as the gold standard. The preliminary results indicated that diagnosis of GDM made based on capillary blood glucose 2 hour post glucose load ( $2 \mathrm{hBG}$ ) had a sensitivity of $100 \%$ and specificity of $100 \%$ when compared to that of the standard autoanalyser method.

\section{Results}

Of 1036 pregnant women who fulfilled eligibility criteria sixteen refused, and from 1020 who entered the study 56 were lost to follow up, yielding a nonparticipation rate of $1.5 \%$ and loss to follow up rate of 5.5\%. Of 964 study subjects 91 reported an abortion (9.4\%) before the OGTT at 24-28 weeks, and yet another $20(2 \%)$ were unable to tolerate an oral glucose load, thus yielding 853 women who completed both phases of the study. Table 2 shows the validity of individual

Table 1. Values for diagnosis of diabetes mellitus and other categories of hyperglycaemia (WHO recommendations, 1999) (Reference 6)

\begin{tabular}{|c|c|c|c|}
\hline & \multicolumn{3}{|c|}{ Glucose concentration, $\mathrm{mmol} / \mathrm{l}(\mathrm{mg} / \mathrm{dl})$} \\
\hline & Whole blood venous ${ }^{1}$ & Whole blood capillary ${ }^{2}$ & Plasma* $^{*}$ venous ${ }^{3}$ \\
\hline \multicolumn{4}{|l|}{ Diabetes mellitus } \\
\hline Fasting & $\geq 6.1(\geq 110)$ & $\geq 6.1(\geq 110)$ & $\geq 7.0(\geq 126)$ \\
\hline 2-h post-glucose load & $\geq 10.0(\geq 180)$ & $\geq 11.1(\geq 200)$ & $\geq 11.1(\geq 200)$ \\
\hline \multicolumn{4}{|c|}{ Impaired glucose tolerance (IGT) } \\
\hline Fasting (if measured) and & $<6.1(<110)$ & $<6.1(<110)$ & $<7.0(<126)$ \\
\hline 2-h post-glucose load & $\geq 6.7(\geq 120)$ and & $\geq 7.8(\geq 140)$ and & $\geq 7.8(\geq 140)$ and \\
\hline & $<10.0(<180)$ & $<11.1(<200)$ & $<11.1(<200)$ \\
\hline \multicolumn{4}{|c|}{ Impaired fasting glycaemia (IFG) } \\
\hline Fasting & $\geq 5.6(\geq 100)$ and & $\geq 5.6(\geq 100)$ and & $\geq 6.1(\geq 110)$ and \\
\hline \multirow[t]{2}{*}{ 2-h post-glucose load } & $<6.1(<110)$ & $<6.1(<110)$ & $<7.0(<126)$ \\
\hline & $<6.7(<120)$ & $<7.8(<140)$ & $<7.8(<140)$ \\
\hline
\end{tabular}

*Corresponding values for capillary plasma are: for Diabetes Mellitus, fasting $\geq 7.0(\geq 126), 2-\mathrm{h} \geq 12.2(\geq 220)$; for Impaired Glucose Tolerance, fasting $<7.0(<126)$ and $2-\mathrm{h} \geq 8.9(\geq 160)$ and $<12.2(<220)$; and for Impaired Fasting Glycaemia $\geq 6.1(\geq 110)$ and $<7.0$ $(<126)$ and if measured, $2-\mathrm{h}<8.9(<160)$

${ }^{1,2}$ Accutrend alpha ${ }^{\circledR}$ glucometer, which was validated against the enzymatic colorimetric assay that showed a sensitivity and specificity of $100 \%$

${ }^{3}$ Enzymatic colorimetric assay (Hitachi, Roche), with intra-assay coefficient of variation (CV) of $1.9 \%$ and $1.7 \%$; and inter-assay coefficient of variation (CV) of $1.9 \% \mathrm{~L}$ and $3.4 \%$ at glucose values of $363.6 \mathrm{mg} / \mathrm{dl}$ and at $43.2 \mathrm{mg} / \mathrm{dl}$, respectively

Table 2. Validity of the screening tests for GDM performed at 24-28 weeks of POA in the community survey

\begin{tabular}{lcccccc}
\hline Screening test & $\begin{array}{c}\text { Sensitivity } \\
(\%)\end{array}$ & $\begin{array}{c}\text { Specificity } \\
(\%)\end{array}$ & $\begin{array}{c}\text { Positive } \\
\text { predictive } \\
\text { value (\%) }\end{array}$ & $\begin{array}{c}\text { Negative } \\
\text { predictive } \\
\text { value (\%) }\end{array}$ & $\begin{array}{c}\text { Likelihood } \\
\text { ratio of a } \\
\text { positive test }\end{array}$ & $\begin{array}{c}\text { Likelihood } \\
\text { ratio of a } \\
\text { negative test }\end{array}$ \\
\hline (a) Random urinary Benedict's test & 10.4 & 99.2 & 54.8 & 92.8 & 13.0 & 0.9 \\
(b) Random urinary Dipstick test & 16.6 & 98.8 & 55.0 & 93.3 & 13.7 & 0.8 \\
*Postprandial urinary Benedict's test & 52.2 & 94.5 & 46.3 & 96.1 & 9.5 & 0.5 \\
*Postprandial urinary Dipstick test & 68.7 & 90.4 & 38.0 & 97.1 & 7.2 & 0.3 \\
Fasting capillary blood glucose & & & & & & \\
cut-off 4.1 mmol/1 (74 mg/d)*** & 62.6 & 73.0 & 16.6 & 95.7 & 2.3 & 0.5 \\
$\begin{array}{l}\text { Presence of risk factors proposed by ADA } \\
\text { **Post-glucose capillary BG cut-off }\end{array}$ & 93.1 & 22.2 & 9.9 & 97.1 & 1.2 & 0.3 \\
7.2 mmol/1 (130 mg/dl)*** & 98.5 & 95.2 & 64.0 & 99.9 & 20.5 & 0.02 \\
\hline
\end{tabular}

*Urine sample taken two hours after the ingestion of standard $75 \mathrm{~g}$ glucose load

**Capillary blood sample taken two hours after ingesting $75 \mathrm{~g}$ glucose load

***Cut-off values determined using ROC curve 
Table 3. Predictive value of fasting plasma glucose of $75 \mathrm{~g}$ OGTT performed in a laboratory setting in diagnosing GDM

\begin{tabular}{|c|c|c|c|c|c|}
\hline $\begin{array}{l}\text { Cut-off value for FPG } \\
\mathrm{mmol} / \mathrm{l}(\mathrm{mg} / \mathrm{dl})\end{array}$ & Specificity & 1-Specificity & Sensitivity & $\begin{array}{c}\text { Positive predictive } \\
\text { value }\end{array}$ & $\begin{array}{c}\text { Negative predictive } \\
\text { value }\end{array}$ \\
\hline $7.0(126)$ & 1 & 0 & 0.035 & 1 & 0.842 \\
\hline $6.1(110)$ & 0.997 & 0.003 & 0.167 & 0.923 & 0.86 \\
\hline $5.8(105)$ & 0.993 & 0.007 & 0.25 & 0.878 & 0.872 \\
\hline $5.6(100)$ & 0.978 & 0.022 & 0.313 & 0.738 & 0.89 \\
\hline $5.3(95)$ & 0.946 & 0.054 & 0.4792 & 0.633 & 0.903 \\
\hline $5.0(90)$ & 0.852 & 0.148 & 0.618 & 0.45 & 0.92 \\
\hline $4.7(85)$ & 0.687 & 0.313 & 0.792 & 0.33 & 0.944 \\
\hline $4.4(80)$ & 0.461 & 0.539 & 0.903 & 0.246 & 0.961 \\
\hline $4.2(75)$ & 0.191 & 0.809 & 0.972 & 0.19 & 0.972 \\
\hline $3.9(70)$ & 0.045 & 0.955 & 1 & 0.17 & 1 \\
\hline
\end{tabular}

screening tests used for detecting GDM at 24-28 weeks of POA.

\section{HOSPITAL BASED CONFIRMATION OF GDM WITH $75 \mathrm{~g}$ OGTT}

\section{(a) How predictive is the fasting plasma glucose?}

The objective of this component of the study was to determine the sensitivity, specificity and predictive value of fasting plasma glucose (FPG) of the OGTT in diagnosing GDM.

\section{Method}

High risk women were screened by performing the $75 \mathrm{~g} 2$ hour OGTT in the unit's laboratory the morning after an overnight fast of at least 8 hours and not exceeding 14 hours, and following at least 3 days of unrestricted carbohydrates ( $>150 \mathrm{~g}$ per day) and exercise as per WHO guidelines [6]. The OGTT was performed between 24 and 28 weeks POA by taking whole venous blood at 0 hours (before) and 1 and 2 hours after ingestion of glucose. Plasma glucose was tested using an enzymatic colorimetric assay (Hitachi, Roche). A plasma glucose concentration at 2 hours when $>7.8 \mathrm{mmol} / 1(140 \mathrm{mg} / \mathrm{dl})$ was considered to confirm GDM as per WHO criteria, provided there was a peak rise at 1 hour.

We analysed retrospectively 999 consecutive OGTTs performed on pregnant women with risk factors who presented to the antenatal clinic, University Unit, De Soysa Hospital for Women from April 2003 to November 2003. Those in whom the 2-hour plasma glucose exceeded the 1 hour value (lag curve) were excluded.

\section{Results}

$116 / 999$ subjects $(11.6 \%)$ had a lag curve and were excluded and the analysis confined to 883 data sets. $144 / 883(16.3 \%)$ patients had an abnormal OGTT based on WHO criteria, of whom 4 (2.6\%) had a FPG $>7 \mathrm{mmol} / \mathrm{l}$ $(126 \mathrm{~g} / \mathrm{dl})$ and $24(16.7 \%)$ had a FPG $>6.1 \mathrm{mmol} / 1$
$(110 \mathrm{mg} / \mathrm{dl})$. The sensitivity and specificity for different concentrations of FPG are shown in Table 3.

\section{(b) What should be the threshold of the two-hour plasma glucose of the $75 \mathrm{~g}$ OGTT to predict the need for insulin treatment in Sri Lankans with GDM?}

The objective of this component of the study was to determine the predictive value of the 2 hour plasma glucose $(2 \mathrm{hPG})$ concentration of the abnormal $75 \mathrm{~g}$ OGTT in Sri Lankan pregnant diabetics.

\section{Method}

We randomly selected pregnant women identified during the current gestation with $2 \mathrm{hPG}>7.8 \mathrm{mmol} / 1$ $(140 \mathrm{mg} / \mathrm{dl})$ in the $75 \mathrm{~g}$ OGTT (WHO criteria) and attending the specialist diabetic clinic at De Soysa Hospital for Women University Unit, Colombo between March-June 2003. They were studied prospectively for their serial 6point plasma glucose profile over 24 hours, their maternal diabetic management requirements (viz. dietary restriction alone or diet combined with insulin), and pregnancy outcome (viz. perinatal mortality and birth weight). The need for antenatal insulin injections based on serial plasma glucose profiles after dietary modification, were matched against the $2 \mathrm{hPG}$ value of the OGTT performed between 24-28 weeks gestation. Their demographic data, family history, pregnancy outcome and birth weight were recorded.

\section{Results}

Sixty-six randomly selected women with abnormal OGTT were studied. $45(68 \%)$ had a $2 \mathrm{hPG}$ $\geq 8.9 \mathrm{mmol} / \mathrm{l}(160 \mathrm{mg} / \mathrm{dl})$, of whom $37(82 \%)$ required insulin therapy during pregnancy and 8 were managed on dietary intervention alone. Of the 21 women with $2 \mathrm{hPG}$ $<8.9 \mathrm{mmol} / 1$ one woman $(4.8 \%)$ required insulin. The $2 \mathrm{hPG}$ value of the OGTT at a threshold of $8.9 \mathrm{mmol} / 1$ had a sensitivity of $97.2 \%$, specificity of $71.4 \%$, positive predictive value of $82.2 \%$ and negative predictive value of $95.2 \%$. Table 4 shows the predictive values of $2 \mathrm{hPG}$ in 
Table 4. Predictive value of the two hour plasma glucose of the $75 \mathrm{~g}$ OGTT for needing insulin therapy for GDM in $\mathrm{mmol} / \mathrm{l}(\mathrm{mg} / \mathrm{dl})$

\begin{tabular}{lcccc}
\hline $\begin{array}{l}\text { 2h PG value } \\
\text { of OGT }\end{array}$ & $\begin{array}{c}\text { Sensitivity } \\
\text { (\%) }\end{array}$ & $\begin{array}{c}\text { Specificity } \\
(\%)\end{array}$ & $\begin{array}{c}\text { Positive } \\
\text { predictive } \\
\text { value (\%) }\end{array}$ & $\begin{array}{c}\text { Negative } \\
\text { predictive } \\
\text { value (\%) }\end{array}$ \\
\hline $7.8(140)$ & 100 & 26.2 & 60.8 & 100 \\
$8.3(150)$ & 97.9 & 40.5 & 65.3 & 94.4 \\
$8.9(160)$ & 35.8 & 61.9 & 74.2 & 92.9 \\
$9.4(170)$ & 83.3 & 78.6 & 81.6 & 80.5 \\
\hline
\end{tabular}

Table 5. Maternal characteristics and pregnancy outcome in women treated with insulin and dietary modification alone (Student $t$ test, $p$ value significant $<\mathbf{0 . 0 5}$ )

\begin{tabular}{lccc}
\hline & $\begin{array}{c}\text { Dietary and } \\
\text { modification } \\
\text { Insulin } \\
(n=38)\end{array}$ & $\begin{array}{c}\text { Dietary } \\
\text { modification } \\
\text { alone } \\
(n=28)\end{array}$ & P value \\
\hline $\begin{array}{l}\text { Average maternal } \\
\text { age (years) }\end{array}$ & $32.23 \pm 1.55$ & $32.31 \pm 1.37$ & 0.94 \\
$\begin{array}{l}\text { History of diabetes } \\
\text { in first degree } \\
\text { relatives }\end{array}$ & $18(47.4 \%)$ & $14(50 \%)$ & 0.67 \\
$\begin{array}{l}\text { Average birth } \\
\text { weight }(\mathrm{g})\end{array}$ & $3036 \pm 230$ & $2992 \pm 168$ & 0.75 \\
$\begin{array}{l}\text { Perinatal deaths } \\
\text { nerath }\end{array}$ & 0 & $1 *$ & \\
\hline
\end{tabular}

*Had $2 \mathrm{hPG}<8.9 \mathrm{mmol} / 1$

increments from the WHO diagnostic value of $7.8 \mathrm{mmol} / \mathrm{l}$. Table 5 shows that the maternal age of the insulin treated and untreated groups was similar, and the pregnancy outcome of the insulin treated group and diabetic diet alone group had comparable mean birth weight with one perinatal death in the diet alone group.

\section{Discussion}

The underlying assumption that justifies screening programmes for GDM is that early detection and effective control of hyperglycaemia during pregnancy leads to significant reduction in both maternal and perinatal morbidity and mortality [7-9]. The WHO recommends universal screening of pregnant women with the OGTT as the screening test as well as the confirmatory test for GDM [6]. The American Diabetes Association (ADA) recommends the 1 hour glucose challenge test (GCT) as a screening test, and the positives to be followed up with the $100 \mathrm{~g} 3$ hour OGTT [2]. We previously reported that the GCT had lower predictive value as a screening test than conventional risk factor identification in a hospital based study in Colombo, Sri Lanka [10].

Our maternal and child health $(\mathrm{MCH})$ system needs to be recommended a screening test with a reasonably high degree of sensitivity, specificity and positive predictive value that is less expensive, non invasive and more acceptable, which could be implemented through the prevailing $\mathrm{MCH}$ infrastructure. This would enable universal screening for GDM when subjects positive for the screening test need to be subjected to the diagnostic OGTT. The ideal screening test for GDM should posses a relatively high sensitivity because the penalty associated with missing a case is high since definitive and effective treatment is available. However, increasing the sensitivity of a test invariably compromises its specificity leading to a relatively higher proportion of false positives. If the proportion of false positives is very high the whole purpose of screening will negate the sustainability of the screening programme.

Screening methods recommended by the WHO and ADA are invasive, time consuming, need technically competent personnel, and laboratory and transport facilities that are expensive. The interpretation of laboratory screening tests for GDM are confounded by the changes in maternal carbohydrate metabolism during normal pregnancy; viz. a greater propensity to renal glycosuria and lacotsuria, the maternal state of accelerated starvation causing lowering of blood glucose in the fed and fasting states, delayed gastric emptying leading to lag curves of the OGTT, increased insulin resistance after 24 weeks of gestation [11], and the blood sample and laboratory test method used to determine blood/plasma glucose concentrations (Table 1) [6].

\section{COMMUNITY BASED SCREENING FOR GDM}

Our national $\mathrm{MCH}$ system currently performs the Benedict's test for random glycosuria to screen for GDM at every antenatal visit. When we validated this test against the OGTT, it yielded a sensitivity of $10 \%$ or would have missed $90 \%$ of subjects with GDM (false negatives), while $45 \%$ of the positive tests did not have GDM (false positives). Hence, the Benedict's test has poor sensitivity and is an unacceptable screening test for GDM. The use of semi-quantitative enzyme based test strips (Dipstick ${ }^{\circledR}$ ) to detect glycosuria gave a marginal benefit of a sensitivity of $16.4 \%$. The sensitivity of detecting glycosuria was improved to some extent by using postprandial urine samples. When Benedict's test to detect postprandial glycosuria was validated, it reported a sensitivity of $52.2 \%$ and a false negative rate of $47.8 \%$, while $53.7 \%$ of positive results did not have GDM (false positives). Validating the postprandial glycosuria Dipstick $^{\circledR}$ test reported a sensitivity of $68.7 \%$ and a false positive rate of $62 \%$. Hence, testing for postprandial glycosuria is better than testing for random glycosuria in the screening for GDM, as previously reported [12]. When we compared the likelihood ratio of a negative result between the two urinary tests, the postprandial Dipstick ${ }^{\circledR}$ test was superior with a lower value (0.3) when compared to the postprandial Benedict's test (0.5). However, its moderate sensitivity and relatively high false positive rate negates its use as the ideal universal screening tool for GDM.

The WHO and ADA do not advocate using fasting blood glucose (FBG) as a screening test for GDM. Hence, 
we first calculated the appropriate threshold for FBG by using the receiver operator characteristic (ROC) curve, which was $4.1 \mathrm{mmol} / 1(74 \mathrm{mg} / \mathrm{dl})$. When we validated FBG of $4.1 \mathrm{mmol} / \mathrm{l}$ to detect GDM, it reported a sensitivity of $62.6 \%$, a false negative rate of $37.4 \%$, and false positive rate of $83.4 \%$ making it unsuitable as a screening test. Risk factors associated with GDM if proven valid will offer a simple screening method for GDM. Screening with selectivity criteria proposed by ADA [2] revealed a sensitivity of $93.1 \%$, false negative rate of only $6.9 \%$, but a high false positive rate of $90.1 \%$. Hence, using risk factors as a screening test, without additional cost or effort, could prevent $21 \%$ of this population being exposed to the invasive and costly OGTT. Nevertheless, its drawback is its high false positive rate. The WHO and ADA do not advocate using postprandial (after a $75 \mathrm{~g}$ standard glucose load) blood sugar test $(2 \mathrm{hBG})$ alone as a screening test for GDM. Hence, we first calculated the appropriate cutoff value by using the ROC curve method, and the calculated threshold was $7.2 \mathrm{mmol} / 1(130 \mathrm{mg} / \mathrm{dl})$. Validating capillary $2 \mathrm{hBG}$ at a threshold of $7.2 \mathrm{mmol} / 1$ to detect GDM reported a sensitivity of $98.5 \%$, a specificity of $95.2 \%$ i.e. true negatives and a false positive rate of $36 \%$.

In summary, this community based study demonstrates that capillary blood glucose 2 hours following $75 \mathrm{~g}$ glucose loading validates satisfactorily against the OGTT, while all other screening tests are ineffective at field level. This also confirms that the current screening practice adopted in our MCH system is suboptimal. Testing for postprandial glycosuria by enzyme based test strips might be a better alternative, at least for an interim period, until our MCH system is able to implement optimal screening. Selecting mothers for OGTT based on risk factors proposed by ADA can be implemented without additional cost through our $\mathrm{MCH}$ system. Its main drawback is that nearly $80 \%$ of pregnant women will have to undergo diagnostic OGTT; which makes the cost and effort similar to implementing universal screening by OGTT as proposed by WHO. We therefore propose capillary post $75 \mathrm{~g}$ glucose test at a diagnostic threshold of $7.2 \mathrm{mmol} / 1$ $(130 \mathrm{mg} / \mathrm{dl})$ as the ideal screening test to be applied at 24-28 weeks of POA in the field setting. In view of its $36 \%$ false positive rate leading to subjects with a positive result having to undergo an unwarranted OGTT, it is essential to conduct an in depth cost analysis to prove that this test has an advantage over universal screening with OGTT.

\section{HOSPITAL BASED CONFIRMATION OF GDM WITH $75 \mathrm{~g}$ OGTT}

When compared with most other endocrine diagnostic procedures the $75 \mathrm{~g}$ OGTT is relatively less expensive, less invasive and more acceptable particularly when limited to three plasma glucose estimations at 0 hours prior to glucose loading and at 1 and 2 hours post glucose loading. The false positives of the initial screening tool can thereby be excluded and the true positives appropriately managed, which has been the routine practice over the

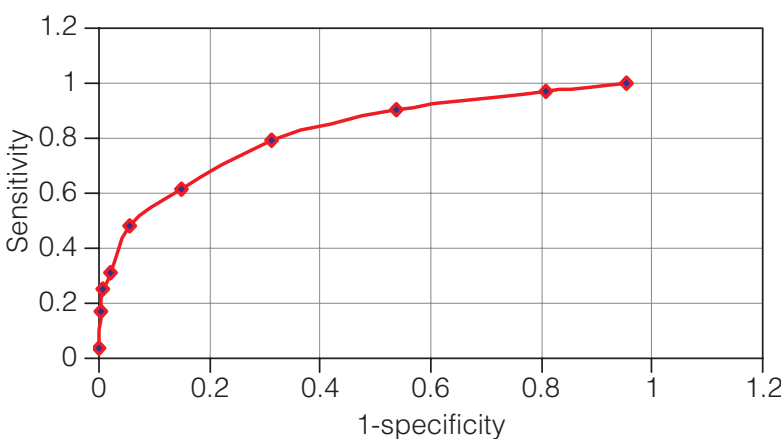

Figure 1. Receiver operator characteristic curve (ROC curve) showing the accuracy of FPG as satisfactory with an area under the curve $=0.84$.

previous decade in our maternity unit based in a tertiary care setting in Colombo. It is appropriate to review our experience with the $75 \mathrm{~g}$ OGTT in terms of its applicability to all health care institutions of the country, and in helping towards optimising its usefulness in the diagnosis and management of GDM. Issues that need to be resolved are to identify the minimum number of blood tests required to be performed in an OGTT, and the predictive value of test results in terms of instituting insulin therapy in the antenatal care of the affected woman.

\section{(a) How predictive is the fasting plasma glucose?}

ROC showed the accuracy of FPG as satisfactory with an area under the curve of 0.84 that yielded a satisfactory sensitivity and specificity at a threshold value of $4.7 \mathrm{mmol} / 1(85 \mathrm{mg} / \mathrm{dl})$ [Figure 1]. However, lowering the FPG threshold increases the sensitivity but reduces specificity and positive predictive value. Perucchini et al [13], who recommended the cut off for FPG as $4.8 \mathrm{mmol} / 1$ $(87 \mathrm{mg} / \mathrm{dl})$ and Rcichelt et al [14], who recommended FPG cut off as $4.7 \mathrm{mmol} / 1$ reported a sensitivity around $80 \%$ when validated against 3 hour $100 \mathrm{~g}$ OGTT. Their findings mirror our experience with the hospital based $75 \mathrm{~g}$ OGTT. The even lower threshold for fasting blood glucose measured in our community based study is likely to be due to red cell utilization of whole blood glucose and the dilution effect of body fluids as reflected in lower diagnostic values for diabetes by capillary whole blood testing compared to venous plasma glucose as depicted in Table 1. Our finding that the value of fasting plasma glucose in diagnosing GDM although improved by lowering the threshold to $4.6 \mathrm{mmol} / \mathrm{l}(84 \mathrm{mg} / \mathrm{dl})$ has a specificity of only $68.7 \%$, leads us to question its actual need when performing the $75 \mathrm{~g}$ OGTT. Furthermore, these results reveal that testing the 2-hour post $75 \mathrm{~g}$ plasma glucose alone as suggested by others from a similar setting [15] would involve a $12 \%$ risk of false positives caused by delayed absorption in pregnancy. Therefore we recommend replacing the fasting plasma glucose test of the $75 \mathrm{~g}$ OGTT with the 1 hour glucose estimation, and thereby limit hospital based screening in the laboratory setting to only two tests. 


\section{(b) What should be the threshold for the two-hour plasma glucose of the $75 \mathrm{~g}$ OGTT to predict the need for insulin treatment among Sri Lankans with GDM?}

We reported in 1997 that the 2-hour post $75 \mathrm{~g}$ OGTT plasma glucose exceeding $8.9 \mathrm{mmol} / \mathrm{l}$ in a hospital based cohort was more predictive of GDM than the $50 \mathrm{~g}$ glucose challenge test [16]. The current prospective study on the treatment requirements of GDM in relation to the $2 \mathrm{~h}$ plasma glucose concentration of the $75 \mathrm{~g}$ OGTT performed at 24-28 weeks pregnancy is in keeping with YonTen's previous reports, in that the threshold value at $8.9 \mathrm{mmol} / 1$ is a good predictor of the need for insulin when managing GDM which leads to a satisfactory pregnancy outcome.

In conclusion, we recommend that in primary care screening for GDM, testing for postprandial glycosuria by enzyme based test strips is a better alternative to the current practice of Benedict's test of random urine, until our MCH system is able to implement universal screening using capillary blood glucose 2 hours following $75 \mathrm{~g}$ glucose loading at 24-28 weeks of pregnancy in the field, following an in depth survey of its cost effectiveness. We also recommend that to confirm gestational diabetes in the hospital laboratory setting the $75 \mathrm{~g}$ OGTT be restricted to two plasma glucose tests performed 1 and 2 hours after glucose loading, and when the 2-hour plasma glucose concentration exceeds $8.9 \mathrm{mmol} / 1(160 \mathrm{mg} / \mathrm{dl})$ following a one hour peak it should alert the health care teams to a high probability of the need for insulin to maintain maternal normoglycaemia in order to achieve satisfactory pregnancy outcome.

\section{Acknowledgements}

Director National Institute of Health Sciences, Kalutara, WHO (for funding), DDHS, MOH, Public Health Nursing Sisters, Public Health Midwives of Homagama DDHS area for their ready support in the community based project.

Head, academic staff, consultants and support staff of the Department of Obstetrics and Gynaecology, Faculty of Medicine, University of Colombo, Sri Lanka; Director and administrative staff of De Soysa Hospital for Women, Colombo, Sri Lanka; Mrs Sumedha Wijeratne, Senior Lecturer in charge, and Laboratory Technical Officers Mrs ASDS Wijeratne, Mrs AUA Gunewardhena and Mrs M Warnakulasuriya for laboratory support.

All pregnant women for their ready co-operation.

\section{References}

1. Expert committee on the diagnosis and classification of diabetes mellitus: report of the expert committee on the diagnosis and classification of diabetes mellitus. Diabetes Care 2003; 26: 5-20.

2. American Diabetes Association: Gestational diabetes mellitus (Position statement). Diabetes Care 2004; 27: 88-90.
3. Metzger BE, Couston DM. Organizing committee: summary recommendations of the fourth international workshop conference on gestational diabetes mellitus. Diabetes Care 1998; 21: 161-7.

4. Ginige S, Wijewardhana K, Wijeyaratne CN. Prevalence of gestational diabetes mellitus in Homagama divisional director of health services area. Journal of the College of Community Physicians of Sri Lanka 2004; 9: 40-2.

5. Dabelea D, Snell-Bergeon JK, Hartsfield CL, Bischoff KJ, Hamman RF, et al. Increasing prevalence of gestational diabetes mellitus (GDM) over time and by birth cohort: Kaiser Permanente of Colorado GDM screening program. Diabetes Care 2005; 28: 579-84.

6. World Health Organization. Definition, diagnosis and classification of diabetes mellitus. Report of a WHO consultation, 1999; WHO/NCD/NCS/99.2.

7. Crowther CA, Hiller JE, Moss JR, McPhee AJ, Jeffries WS, et al. Australian carbohydrate intolerance study in pregnant women (ACHOIS) trial group. Effect of treatment of gestational diabetes mellitus on pregnancy outcomes. New England Journal of Medicine 2005; 352: 2477-86.

8. Pesson B, Hanson U. Neonatal morbidities in gestational diabetes mellitus. Diabetes Care 1998; 21: B57-67.

9. Drexel H, Bichler A, Sailer S, Breir C, Lisch H, et al. Prevention of perinatal morbidity by tight metabolic control in gestational diabetes mellitus. Diabetes Care 1998; 11: $761-8$.

10. YonTen DW, Wijeyaratne CN, Wijeratne S, Seneviratne HR. Screening for gestational diabetes mellitus. Book of Abstracts - Sri Lanka College of Obstetricians and Gynaecologists International Congress 1997; 97.

11. Boden G. Fuel metabolism in pregnancy and in gestational diabetes mellitus. Obstetrics and Gynaecology Clinics of North America 1996; 23: 1-10.

12. Nugegoda DB, Illangasekera U, Perera L. Validity of the postprandial dipstick urine test in detecting diabetes mellitus. Kandy Medical Journal 1993; 2: 45-7.

13. Perucchini D, Fischer U, Spinas GA, Huch R, Huch A, et al. Using fasting plasma glucose concentrations to screen for gestational diabetes mellitus: prospective population based study. British Medical Journal 1999; 319: 812-5.

14. Reichelt AJ, Spichler ER, Branchtein L, Nucci LB, Franco LJ, et al. Fasting plasma glucose is a useful test for the detection of gestational diabetes. Brazilian study of gestational diabetes (EBDG) working group. Diabetes Care 1998; 21: 1246-9.

15. Senanayake H, Ariyaratne H, Wijeratne S. Is there a place for a single value oral glucose tolerance test for the diagnosis of gestational diabetes mellitus Ceylon Medical Journal 2005; 49: 136.

16. YonTen DW, Wijeyaratne CN, Seneviratne HR. The role of the 2 hour OGTT value in the management and outcome of diabetic pregnancy. Book of Abstracts-Sri Lanka College of Obstetricians and Gynaecologists International Congress 1997; 25. 